\title{
Review on Blackleg in Cattle
}

\author{
Tolera Tagesu*, Tagesu Abdisa, Roba Hasen, Gemachu Regea and Getachew Tadesse \\ School of Veterinary Medicine, Jimma University, Ethiopia
}

Submission: January 12, 2019 ; Published: February 05, 2019

*Corresponding author: Tolera Tagesu, Jimma University, School of Veterinary Medicine, Jimma, Oromia, Ethiopia

\begin{abstract}
Blackleg is an endogenous acute infection that principally affects cattle. Blackleg is generally fatal bacterial diseases of young cattle or sheep of any age. The disease is caused by Clostridium chauvoei, an anaerobic spore forming bacterium seen as an acute, localized inflammation of muscle tissue due to growth of the blackleg organisms. This followed by generalized toxemia or poisoning of the animal causing rapid death. The disease is widely distributed in the world. Blackleg can occur at any time of the year; more loss of cattle is seen during warm months of the year. Blackleg has been found in cattle as young as two-month-old, most loss occur in cattle, the best conditioned animals, where there is an abundance of feed. It is prevented by vaccination when out breaks occur; in early stage of the disease it is treated by antibiotic mostly penicillin is effective treatment to the disease. Control of this disease is based on stringent husbandry measures and scheduled vaccination plan. In recent years, the major virulence factors of $\mathrm{C}$. chauvoei have been discovered and described. However, the pathogenesis of blackleg in cattle and, circulation of the pathogen from point of entry to target tissues is yet not fully elucidated. Therefore, the objectives of this paper are to summarizes the latest review of literature that significantly contributed for understanding the disease in cattle and provides a foundation to preventive strategies.

Keywords: Blackleg; Cattle; Clostridium chauvoei; Soil; Vaccination
\end{abstract}

\section{Introduction}

Ethiopia is one of the countries with the largest number of livestock in Africa and livestock production plays a major role in the development of Ethiopia's agriculture. Ethiopian livestock population is estimated to be 59.49 million cattle, 30.697 million sheep, 30.200 million goats, 8 million donkey, 2.16 million horse, 1.20 million camels, 0.4 million mules and 59.495 million poultry [1]. Nevertheless, the development of livestock sector in Ethiopia is hindered by widespread endemic health problems including bacterial diseases, viral diseases, and parasitic infestation [2].

Animal diseases such as blackleg which is also called quarter ill or black quarter cause the major limitation to the livestock agriculture of the country and affect livelihood through their effect on animal health and impact on the production. Blackleg also called quarter ill or black quarter is an acute specific infectious disease of cattle, sometimes of sheep and pigs characterized by the presence of rapidly increasing swellings containing gas, and occurring in the region of the shoulder, neck, thigh, quarter, and sometimes in the diaphragm. Young cattle between the ages of 6 months and 2 years are also susceptible [3]. The disease is an acute myositis caused by the activation of latent intramuscular Clostridium chauvoei spores. It commonly kills unvaccinated cattle between 3 months and two years of age especially in higher rainfall areas such as the coast of north southwest. It is an endogenous acute infection that principally affects cattle. The disease is caused by Clostridium chauvoei (C. chauvoei), an anaerobic spore forming bacterium. Blackleg usually commences in skele tal muscles but occasionally the heart or diaphragm is affected. The primary site of infection of blackleg was myocardium [4].

Blackleg is caused by the spore forming, rod shaped, gas producing bacteria Clostridum chauvoei. The spores of the organisms can live in the soil for many years. The bacteria enter to the host by ingestion and then gains entrance to the body through small punctures in the mucous membrane of the digestive tract. Cattle that are on a high plane of nutrition, rapidly gaining weight and between 6 months and 2 years of age are most susceptible to the disease. The disease is not transmitting directly from sick animal to healthy animals by contact [3].

Bacterial spores are eaten in contaminated feed or soil. The spores then eater the bloodstream and lodge in various organs and issues, including muscles. The injury reduces load flow to the area, thereby reducing the supply of oxygen to tissues. In the absence of oxygen, the spores germinate and multiply. As they grow, the bacteria produce toxin which destroy surrounding tissues. The toxins are absorbed in to the animals' blood stream which makes the animal acutely sick and causes rapid death [5]. The first signs observed are usually lameness; loss of appetite, rapid breathing and the animal is usually depressed and has a high fever, characteristic swellings develop in the hip, shoulder, chest, back, neck or elsewhere. First the swelling is small, hot and painful. As the disease progresses, the swelling enlarges and becomes spongy and gaseous. If the swelling is pressed, gas can be felt under the skin. The animal usually this within 12 to 48 
hours. In most cases the animal is found dead without being previously observed sick.

Pathological changes associated which blackleg are the carcass bloats and putrefies quickly after death, body cavity often contain excess fluid, often reddish in color, infected muscle masses are swollen, discolored and have a foul odor, in some cases a small muscle mass will be affected and lesions may be hard to find. Sporulated gram positive rods can be demonstrated in smears of infected tissues and identified by immune florescent reagent. ground muscle in saline is cultured on blood agar plates, which are incubated anaerobically, because of the possible presence of swarming $\mathrm{Cl}$, septicum, early subcultures should be attempted from some plates, which others last for 48 hours most the organism will appear as gram positive rods when examined immediately following death of the animal [6].

Treatment of affected animas with penicillin is logical if the animal is not moribund but results are generally any fair because of the lesion. Large doses should be administered commencing with crystalline penicillin intravenously and followed by longer acting preparation, some of which should be given in to the affected issue if it is accessible. The most effective means of prevention is proper vaccination program. Multivalent vaccine is suggested. The first dose should be given at two months of age and a second injection at either four weeks before preweaning or at the time of weaning. If animals are in an endemic area, another booster should be given [7].

In the event of an outbreak, individuals between 6 months and 2 years should be vaccinated or revaccinated. A two-week period post vaccination exists during which antibody levels are not high enough to our resistance and animals may continue to be loss. Moving animals away from the site of contamination is desired but even this is not always effective. Carcasses of animals known to have died from blackleg should be not opened. Opening the carcass can liberate bacteria which with form sports that with contaminate the ground and subsequently infect other cattle [8]. Blackleg is a cause of severe financial loss to cattle raisers in many parts $f$ the world. Outbreaks still occur occasionally in vaccinated herds but more frequently in herds where vaccination has been neglected [6].

\section{Literature Reviews}

\section{Etiology}

Clostridium chauvoei the causative agent for blackleg is an anaerobic, highly pathogenic, endospore forming and gram-positive bacterium, which produces lemon-shaped endospores and requires enriched media for growth [9]. The spores are highly resistant to environmental changes and disinfectant and persist in soil for many years and the organisms are typically pleomorphic. False blackleg may be caused by $\mathrm{Cl}$. Septicum and Cl. novyi but this disease is more accurately classified as malignant edema. In 2013 , the first draft genome sequence of a virulent C. chauvoei strain became known, consisting of 2.8 million base-pairs [10].
The relatively small genome of $\mathrm{C}$. chauvoei as compared to other Clostridium species, such as C. difficile i.e. 4.2 million base pairs [11], reflects its adaptation to a restricted host range (bovine, caprine and ovine), where C. chauvoei can replicate and to cause disease [12].

C1.chauvoeiis motile and have peritrichaous flagella spores which are formed on solid media and in broth are oval, occurring central or sub terminal positions and distort the shape of the sell. They are resistant to the effects of boiling in water as well as to phenolic and quaternary disinfectants $\mathrm{C} 1$. chauvoei has high requirements regarding culture media and culture conditions under an aerobic conditions irregular vine leave stepped translucent or opaque the optimal in cubation temperature is $37^{\circ} \mathrm{C}$.

\section{Epidemiology}

\section{Source of infection}

Blackleg is a soil born infection but the portal by which the organisms enter the body is through the alimentary mucosa after ingestion of contaminated feed. The bacteria may be found in the spleen liver and alimentary tract of the last soil and pasture may occur from infected feeds or decomposition of carcasses of animal dying of the disease. True black leg develops when spores which are lodged in normal tissue and proliferate by mechanism such as trauma or toxemia [6].

Mode of transmission: In sheep the disease is almost always wound infection. Infection of such wounds at hearing and docking and of the novel of birth may cause the development of local lesson. Infections of the vulvas and vagina of the ewe and rams up to year old, usually as a result of infection of skin would case by fighting. Occasional out breaks have occurred in sheep after vaccination against enterotoxaemia. Ewes exposed to infection at shearing develop typical lesion but ewes traded with penicilling are un affected except that the present ewe in the letter group shown distended abdomens, weakness and recumbence due to edema and gas formation in cattle mainly transmitted through ingestion of spores [6].

Occurrence of blackleg: Blackleg is primarily a disease of pastured cattle, although sheep may also be affected. It preferentially affects animals under two years of age, with most cases occurring in cattle from four to 24 months of age [13]. Occurrence of the disease is worldwide, although it tends to be localized, even to certain farms or to certain pastures. Because of this localization, it is assumed that C. chauvoei is soil borne, but likely does not grow in soil. The bacteria grow readily in the intestinal tract of cattle and may be recycled through fecal contamination of the soil. Once exposed to the environment, C. chauvoei readily forms spores, which may survive for long periods (many years) in the soil [14]. The disease occurs usual for a number animal to be affected within the space of a few days. The disease is endemic areas, especially when they are subject to flooding such as area may vary in size form group of forms to on individual field are created late in black leg approaches $100 \%$ [6]. 


\section{Risk Factor}

Animal risk factor: True blackleg is usually thought as disease of cattle and occasionally sheep but out breaks of the disease has been recorded in deer and in one case in a horse. In cattle the disease is largely confined to young stock between the age of 6 month and 2 years. In the field the disease appears to occur most frequently in rapidly growing cattle on a high plane of nutrition. Elevation of the nutritional status of sheep by increased protein feeding increases their susceptibility to blackleg. In sheep there is no restriction to age group [15].

Environmental risk factor: Typical blackleg of cattle has seasonal incidence with most cases occurring in the warm month of the year. The highest incidence may vary from spring to autumn, depending probably on when calves reach the susceptible age group some outbreak of blackleg in cattle have occurred following excavation of soil which suggests that disturbance in soil may expose and activate latent spores [8].

\section{Pathogenesis}

The detailed pathogenesis of blackleg is still somewhat uncertain, but many of the critical points in the following proposed sequence of events have been confirmed in the natural disease and in experimental infections in cattle [16]. The spores are ingested from soil, enter the gastrointestinal tract and, by hematogenous route, reach the muscle where the spores remain latent in cells of the mononuclear phagocytic system. The spores may remain latent in the muscle for years $[4,17,18]$. Transient trauma or ischemia of the muscle favors the germination of the spores and secretion of cytolytic toxins that cause necrosis of vascular endothelia (edema, hemorrhage) and myofibers. The toxins are absorbed into the animal's bloodstream which makes the animal acutely sick and causes rapid death. Clostridial proliferation yield gas which appears as bubbles between the muscle's bundles [19] (Figure 1).

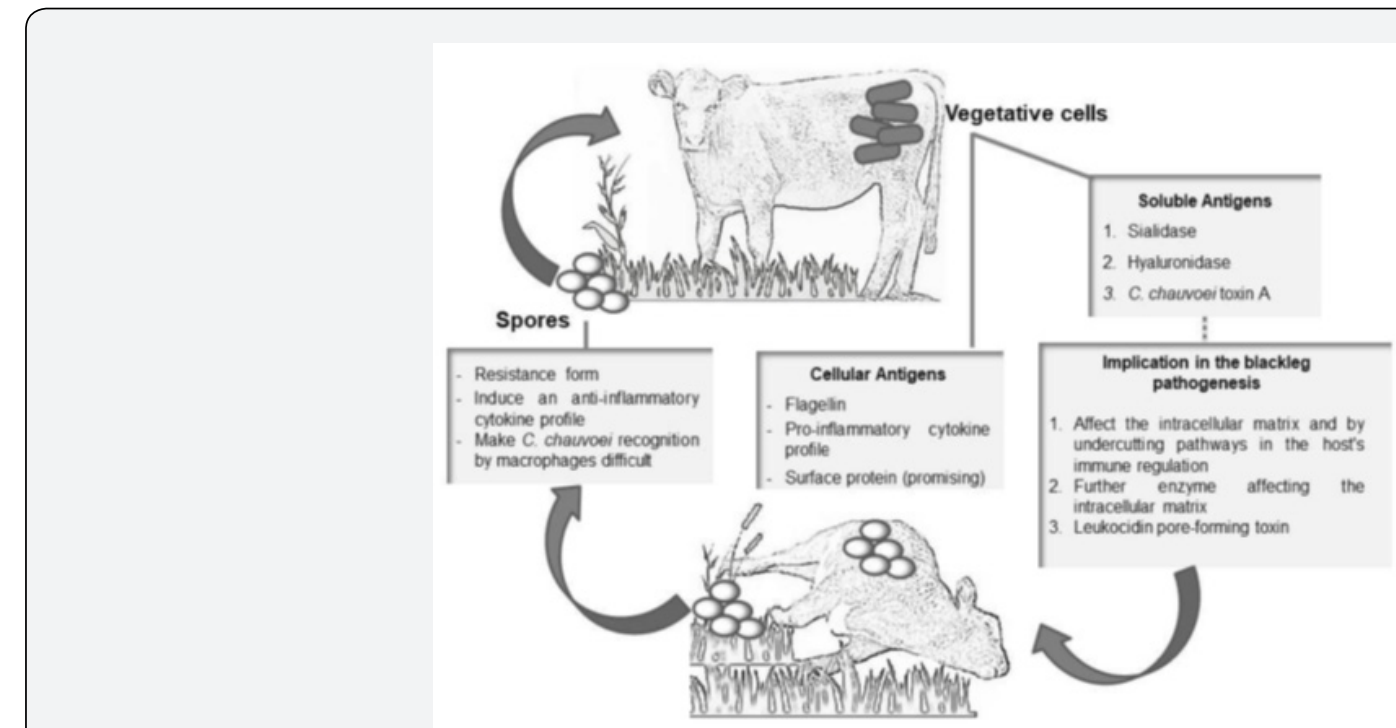

Figure 1: Schematic illustration of blackleg pathogenesis involving currently considered major virulence factors.

\section{Clinical presentations}

Clinical signs of blackleg have been well-documented, but due to the sudden onset and often per acute nature of the disease, are not often observed in field cases [20]. The disease runs on acute, usually fatal course, and affected animals are often found dead before signs of illness have been observed. In some cases, there may be lameness or visible swelling of muscle groups. Any striated muscle may be affected, including the tongue diaphragm, and myocardium, but are shoulder and pectoral muscles are most often involved [21]. It should be suspected if an animal affected between 6 months and two years become lame with swelling of muscle, stops grazing appear sick a quietly goes down. How, these signs are usually of such short duration that they may be missed more frequently; unthrifty calf or yearling is simply found dead. Gas is detectable under the skin and his produces a crackling sensation when the skin is rubbed with the hand [8].
The rapid accumulation of gas under the skin and in the body, cavity gives the carcass a bloated appearance, with the limbs spread apart and pointing up words. There may be frothy, blood stained discharge from the mouth and nostrils. In Cattle, incubation period is 1-5 day. Sudden onset, Lameness, common. Marked depression, temperature normal when animal signs are evident. Edematous, crepitate, subcutaneous swellings over hips, shoulder, chest or back, Swelling, hot and painful initially later enlarge; become creping with cold, insensitive skin, tremors, prostration, the course of clinical disease is rapid, and most animals die within 12 to 36 hours of the onset of clinical signs [13].

In sheep, like cattle, but swelling usually occurs at wound site, Lameness primary symptom, swelling in perineum to pelvis following parturition [8]. In cattle the most obvious sign is crepitate swelling particularly in the hip or hindquarter which oracles when rubbed with the fingers as a result of large quantity of gas produced subcutaneously by the organism. In sheep an acute fe- 
brile condition develops within 1-2 days following an injury and atypical black quarter lesion can be observed near the site [22].

\section{Postmortem findings}

Cattle found dead of blackleg are often in characteristic position, lying on the side with the affected hind limb stands out stiffly. Bloating and putrefaction occur quickly and blood-stained froth exudates from the nostrils and anus. Clotting of the blood occurs rapidly. Lesions resulting from C. chauvoei infection are typically within the larger muscle groups of the limbs. The affected area is dark red, within which small areas of necrosis may be observed [23]. The muscle is typically dry and spongy, with small gas bubbles separating muscle bundles, with little edema centrally. Incision of the affected muscle mass reveals the presence of dark, discolored, swollen tissue with rancid odor on the cut surface and an excess of serosanguineous containing bubbles of gas. In some cases, the myocardial muscle and diaphragm may be the only tissues offered [24].

The following are some pathological changes associated with blacklegs in cattle; the carcass bloats and putrefies quickly after death, body cavities often contain excess fluid, often reddish in color, infected muscle masses are swollen, discolored and have a foul odor, in some cases a small muscle mass will be affected and lesions may be hard to find [25]. In locations such as the tongue, myocardium, and diaphragm, the lesion may be small and escape detection during postmortem examination, but still producing enough bacterial toxins to be lethal to the animal. All skeletal muscle of the body those of the lumbar region must be examined for evidence of the lesion, which may be small and escape carefully examination. All body cavities contain excess fluid which contain variable amount of fibrin and is usually blood stained. The solid organs show some degree of degeneration, and post mortem decomposition with the production of gas in the liver occurs rapidly.

\section{Gross lesion}

The gross appearance of the muscle varies with the age of the lesion. In the early stages the periphery of the lesion the muscle is dark red and markedly distended by serous or seroheamorrhagic exudates, which separates the fiber the cut surface is wet, and exudates may drip out. In the advanced stage, the center of the lesion is dry reddish black, and porous because of gas bubbles. In the control part of the lesion there is usually well-defined area of muscle which is dark red in color, dry, necrotic and filled with small gas bubbles which give a swollen appearance of the muscle. The lesion has characters rancid dour like that produced by culture of a chauvoei growing in cooked meat broth medium. Surrounding central area, the muscle becomes pinker ad there is variable amount of either yellow or blood-stained edematous fluid which is particularly obvious in the local connective tissue. Perineum lesion is ewes which have recently lambed includes neurosis of the vaginal mucous and skin, and extensive edema often involving the hind limbs and thigh muscles which are swollen and dark in color [22].
Gross changes elsewhere in the body are directly referable to either toxemia or proliferation of bacilli. Because of the pyrexia cadavers bloat rapidity and undergo rapid postmortem decomposition. Yellow subcutaneous fluid with or without gas bubbles may be associated with affected muscle. Pelvic, pectoral girdle, glutei, femoral, and hummer's scapular muscle are frequently involved, but lesion can be presenting any striated muscle inducing hear trauma of the diaphragm, tongue and masticators muscle. Lesions may be very small and may be detected only if muscles are incised of not more than one $\mathrm{cm}$ interval. When the disease has resulted from infection of skin wounds the lesions are more obvious superficially, with subcutaneous edema and swelling, and involvement of the underlying musculature. When invasion of the genital tract occurs, typical lesions are found in the perinea tissues and in the walls of the vagina and occasionally the uterus. in the special case of pregnant ewes' typical legions may involve the entire fetus and cause abdominal distension in the ewe [6].

\section{Microscopic lesion}

Heart muscle showed severe suppurative and necrotizing myocarditis with extensive necrosis. In addition, multifocal areas of suppurative inflammation were noted in the thymus, and mild colitis was observed. The essential are found in the skeleton musculature. Gas bubbles in the fixed tissue are indicated by spherical spaces separating fixed tissues are indicated by spherical spaces separating muscle bundles and facial. There are irregular areas of necrosis and collections of neutrophils and lymphocytes along the muscle speta, Edema are uncommon. Histopathologic examination of tissues from animals affected by blackleg revealed severe suppurative and necrotizing pneumonia and suppurative and fibrinous pleuritis [26].

\section{Diagnosis}

Clinical: The history of the disease and the symptoms may be strongly suggestive of blackleg but the final diagnosis must depend up on the selection of the causal organisms. CL. chauvoeican be readily demonstrated on films prepared from the lesion and from the edematous fluid [22]. In typical cases of blackleg in cattle a definite diagnosis can be made on the clinical signs and the necropsy findings. However, in many cases the diagnosis may be in doubt because may be confused with other acute clostridia infection with lighting strike and with anthrax though in the latter the characteristic splenic lesion is usually present in establishing diagnosis. When several animals are found dead kept under close observation one must depend on one's knowledge of local disease incidence season of the year age group affected and pasture conditions and on a close inspection of the environment in which the animals have been maintained. Necropsy findings are most availed the carcasses are still fresh but, on many occasions, post mortem delay position is so advanced that little information can be obtained.

Lameness, depression, loss of appetite and a hot painful swelling on a limb which crackles when pressed may indicate 
blackleg. Later the skins over the swelling will be cold, dry and leathery. In areas where blackleg is known problem it should be suspected in cases of sudden death. Post mortem examination usually reveals, somewhere in the body an area of dark red dry muscle confirms by veterinarian, prefer by laboratory examination of tissues from affected animals. Presumptive diagnosis can be made by the characteristic gross legions and by demonstration of numerous single or, possibly, paired bacilli with rounded ends and occasional spores' ear but not at the end of the occasional spores near but not at the end of the cell. As typical of clostridia, the spore is somewhat greater in diameter than the bacillus in which it forms the lesion must be differentiated from other clostridia infections of muscle particularly L. Septicum therefore, the diagnose should be confirmed by culture of use of specified immunological staining techniques [21].

Laboratory diagnosis: Sporulated gram positive rods can be demonstrated in smears of infected tissues and identified with immunofluorescent. Ground muscle in soil is cultured on blood agar plates which are incubated anaerobically. Because of the possible presence of swarming a septicemia early subcultures should be attempted from some plates with others last for $48 \mathrm{hr}$ identification by immunofluorescence or biochemical [27]. Mostly the organism will appear as gram positive rods when examined immediately following death of the animal, but after several hours the lesion will contain greater percentage spores and pleomorphic forms. $\mathrm{Cl}$, chauvoei is a strict anaerobe and grows at high as $500 \mathrm{c}$ though the optimum is $37^{\circ} \mathrm{C}$. It will grow on the usual laboratory media but is best cultivated in meat or brain medium. These are never discolored nor digested by pure cultures, but they may be slightly softened. Muscle necrosis is extensive and associated with gas bubbles hemorrhages [28].

Isolation and culture: The organisms may in cases be isolated in pure culture directly from the tissues infected. Growth in culture Medias quite dependent up on the presence on carbohydrates for the best growth soda content beyond neutrality is advisable. Body fluids or tissues except as they may act as reducing agents or contain carbohydrate don't increase suitability of media containing the. The colonies are spherical or somewhat irregular, which microscopic radiator. In all cases of suspected black leg smears of affected tissue should be made and material collected for bacteriological examination. Pasteur pipettes from muscle tissue and heart blood, and secretion of muscle removed aseptically are suitable simmers for laboratory examination. The isolation and identification of the causal organisms from muscle lesion is difficult because of the rapidity with clostridia invade the tissues from gestor intestinal tract after death and of certain bacteriological species such as $\mathrm{Cl}$, chauvoei and CI. Novyi [6].

\section{Differential diagnosis}

Anthrax: Anthrax is a hemorrhagic per acute disease and the clinical sign is sudden death. Dark tarry discharge from body orifices, absence of rigor mortis, enlarged spleen, degeneration of the liver and kidneys are characteristic postmortem findings in anthrax.
Malignant edema: This disease, commonly called stable blackleg, is very similar to blackleg. In fact, the similarity is so close that often a diagnosis can be made only when the specific bacteria are identified in the laboratory. Furthermore, both organisms may be present in the same outbreak, or even in the same animal. Malignant edema does differ from blackleg in some respects. It is caused by bacteria called Clostridium septicum. It is more common in older animals and is more likely to occur during the winter months than blackleg.

Heart water: Caused by Ehlrichiarumminantum the suddenness of death and the presence of hydro pericardium in sub-acute cases the disease however, demonstration or ehrlichia bodies in the endothelium cells of blood capillaries in the brain and Jugular vein, demonstrated presence of the Amblyomma ticks. Snakebites was also one of the diseases we should have to differentiate from blackleg, since it's a sudden death with lack of clinical signs and occasional per pharyngeal and brisket oedema, can be confused with sub-acute disease. Bites on the muzzle, head and neck are more likely acute systemic sign and death. It is possible to see the marks from the bite and often local swelling tissue discoloration and hemorrhae at the sight or the bite are suggestive of snake bite poisoning [29].

\section{Treatment}

Treatment of affected animals with penicillin and surgical debridement of the lesion, including fasciotomy, is indicated if the animal is not moribund. Recovery rates are low because of the extensive nature of the lesions. Large doses $(44,000 \mathrm{IU} / \mathrm{kg} \mathrm{BW})$ should be administered, commencing with crystalline penicillin intravenously and followed by longer-acting preparations. Blackleg antiserum is unlikely to be of much value in treatment unless very large doses are given [30]. According to [31]; treatment of clostridial myositis is rarely successful due to the rapid course. Antimicrobials (drug of choice procaine penicillin) around affected tissues, aggressive surgical debridement to allow aeration along with supportive treatment can be of value. Majority of cases show poor prognosis. Treatment of affected animals with penicillin is logical if animal not moribund but results are generally any fair because of the extensive nature of the lesion. Large dose should be administered, commencing with crystallin penicillin intravenous and followed by longer acting preparations, some of which should be given in to the affected tissue if it is aquesible. Blackleg antiserum is unlikely to be of much value in treatment unless very large does are giver [6].

The speed which blackleg kills usually make individual treatment useless in some cases, however, animals treated early with antibiotics may survive, although they often suffer permanent deformity due to partial or complete destruction of muscle. Usually of little practical application after symptoms are observed, remove necrotic tissue, administer adequate dosage of penicillin and formalized toxoid [8]. Treatment is often disappointing penicillin should be given intravenously at first followed by repository form intramuscularly, if possible, in to the affected muscle. Antibiotic treatment of affected animals is likely to be effective 
only if commenced early large doses of penicillin should be administered intravenously followed by longer acting preparation, some of which should be given in to the affected tissue. However, because of the extensive tissue involvement, even if the infection is eliminated the subsequent muscle loss is great economic value [6].

\section{Controls and preventions}

If the antibiotics are not given new cases of black leg may occur for up to 14 days unit immunity develops, and constant surveillance and the early treatment of cases will be necessary [32]. On farm where the disease is endemic annual vaccination of all cattle between 6month and two years of age should be carried out just prior to the anticipated danger period usually spring and summer. Vaccination of calves at 3 weeks of age has been recommended when the incidence of the disease is very high movement of the cattle from the affected pasture is advisable. Bacteria prepared from $\mathrm{C} 1$. Chauvoie is preferred. The improvement to be expected would be greater still if the toxin composition of each isolate where known rather than its identifying antigen city. Cattle are vaccinated at 3 to 6 months of age and annually thereafter. Vaccination should precede exposure by at least 2 weeks. It is not possible to prevent clostridial bacteria from being present in the soil, but it is possible to vaccinate animals to prevent the occurrence of the disease. The most effective means of prevention is proper vaccination program. Multivalent vaccine is suggested he first does should be given at two months of age, and a second infection at either four weeks before pre-weaning or at the time of weaning. If animals are in an endemic area another boaster should be given [33].

Attenuated organism is also used in the preparation of vaccines for use in cattle and some attenuated strain of bovine origin or recently isolated, virulent, ovine strain may be used to prepare vaccine for use in sheep. To administer a polyvalent vaccine highly recommended for the extra protection acquired at very little extra cost. Large number of spores which can spread by wind, rain and scavengers. Blackleg vaccination should be routine procedure on all properties in areas where the disease is known to occur. The vaccine be injected under the skin on the side of the neck ensuring that the infection does not go in to the muscles.

Large number of spores which can spread by wind, rain and scavengers. Black leg vaccination should be routine procedure on all properties in areas where the disease is known to occur. Susceptible cattle which in endemic areas must be vaccinated cattle groped on flood- pains or along water courses also should be regularly immunized because of the risk that infection may be introduced with car cases of dead cattle, which may be deposited during flooding. Beef calves are usually vaccinated when they are branded an ear marked, usually at one or four months of age. A booster vaccination administered a month or so after weaning, is generally enough to protect until age immunity supervenes at approximately 24 months of an age. Calves vaccinated before 3 months of age should be revaccinated at four to six months of age and again at weaning [34].

\section{Vaccination techniques and vaccinations break downs}

The vaccine should be delivered just under the skin not in to the muscle. Draw pinch of skin and insert the needle between the skin and the muscle. The loose skin of the neck is convenient. Do not save unused parts of bottles or containers of vaccines for future use, as they can become contaminated with undesirable organisms and/or lose their potency. Destroy and vaccine not used within 24 hours of opening [35]. Modern vaccines are produced under conditions of strict quality control by reputable manufactures. Occasionally, reports are received of apparent failure or vaccines. When investigated, most of these vaccination failures due to: In correct dosing, faulty technique, using time- expired vaccine, vaccine having been subjected to high temperature during storage or transportation.

\section{Disease Status in Ethiopia}

Blackleg is endemic disease in Ethiopia, outbreaks occurring in warm season. Most of the time, when outbreaks occur ring vaccination is given to the herd, there is no any research done in the country based on case morbidity and mortality rate. It is highly prevalent in Dega followed by Weinadega and kola [3640] (Table 1).

Table 1: The prevalence of lameness in urban and pre-urban dairy farms in Addis Ababa milk shed due to blackleg.

\begin{tabular}{|c|c|c|c|}
\hline Category & $\begin{array}{c}\text { Number of Animal } \\
\text { Examined }\end{array}$ & Lame Cases & Percentage \\
\hline Cow & 507 & 61 & 12.1 \\
\hline Heifers & 288 & 6 & 2.1 \\
\hline Young stocks & 15 & 4 & 2.6 \\
\hline Bulls & 17 & 2 & 11.8 \\
\hline Total & 964 & 73 & 7.6 \\
\hline
\end{tabular}

\section{Conclusion and Recommendations}

Blackleg is a disease of young, rapidly growing cattle which may cause the sudden loss of a significant number of animals. Effective vaccines are readily available which should be given routinely in all areas. Blackleg has been found in cattle as young as 2 months old, most losses occur in cattle between 6 months and 2 years of age, man not considered susceptible to this disease, however, extreme caution should be taken when working with dead or blackleg suspected animal. Blackleg is a cause of sever financial loss in many parts of the world. For the most part major out breaks are prevented by vaccination but out breaks still occur, where vaccination has been neglected. Based on the above conclusion the following recommendations are forwarded:

a. Animals must be vaccinated against blackleg to avoid loss.

b. Veterinarians must diagnose the disease clinically or in laboratory and administer appropriate drug to save the life of animals. 
c. When outbreaks occur, the society must inform to veterinarian or any authority in the area and veterinarians must go to the area and rule out before giving vaccine whether the outbreak is blackleg or any other disease.

d. The government should distribute enough doses of blackleg vaccine and drugs as well as well-trained veterinarian to the society.

e. The society should be educated to burn or bury body of dead animals without opening or immediately inform to vet officials if possible.

f. Further study should be conducted on the prevalence, of blackleg in cattle in Ethiopia.

\section{References}

1. CSA (2017) Central Statistical Authority, Federal democratic Republic of Ethiopia, Central Statistical investigatory, Statistical abstract. Addis Ababa, Ethiopia. da Cunha FRC, Figueiredo BJF, Gomes CMT, Garcia GC, Navarro GAP, Pedrosa AL. Serological and Parasitological Study of Bovine Trypanosomiasis in the Microregion of Uberaba, Minas Gerais State, Brazil. JSM Atheroscler 1(3): 1016.

2. Yune N, Abdela N (2017) Epidemiology and economic importance of sheep and goat pox: a review on past and current aspects. J Vet Sci Technol 8(2): 1-5.

3. Boden AD (1998) Diagnostic procedure in veterinary bacteriology and mycology. ( $5^{\text {th }}$ edn), pp. 229-251.

4. Radostits OM, Gay CC, Hinchcliff KW, Constable PD (2007) Veterinary medicine: a textbook of the diseases of cattle, horses, sheep, pigs, and goats. (10 ${ }^{\text {th }}$ edn), W.B. Saunders, Philadelphia, USA, pp. 2156.

5. Merck and Inc (1999) Merck veterinary Manual. ( $8^{\text {th }}$ edn), pp. 439-440.

6. Radostits OM, Blood DC, Gay CC (1994) veterinary medicine, ( $8^{\text {th }}$ edn), Baillier Tindall, London, UK, pp. 608-610.

7. Timony IA (1988) Effectives of passive immunity on immune response in calves vaccinated against clostridium chauvoei blackleg), vet med small animal 73: 1564-1566.

8. Schipper IA (2000) preventive veterinary medicine, text book of animal disease, fargosurget, ( $\left.6^{\text {th }} e d n\right)$, pp. 285.

9. Quinn PJ, Markey BK, Leonard FC, Hartigan P, Fanning S, et al. (2011) Veterinary Microbiology and Microbial Disease, second ed., Ames, Iowa, USA.

10. Falquet L, Calderon-Copete SP, Frey J (2013) Draft genome sequence of the virulent Clostridium chauvoei reference strain JF4335, Genome Announc 1: 4.

11. Sebaihia BW, Wren P, Mullany NF, Fairweather N, Minton R, et al. (2006) The multidrug-resistant human pathogen Clostridium difficile has a highly mobile, mosaic genome, Nat Genet 38(7): 779.

12. Frey J, Falquet L (2015) Patho-genetics of Clostridium chauvoei, Res Microbiol 166(4): 384-392.

13. Parish SM, Valberg SJ (2009) Clostridial myonecrosis. In: Smith BP (Eds.), Large Animal Internal Medicine, ( $4^{\text {th }}$ edn), St. Louis, Mosby. 1400-1402.

14. Van Vleet JF, Valentine BA (2007) Blackleg. In Maxie MG (Eds.), Jubb, Kennedy, and Palmer's Pathology of Domestic Animals, I, Philadelphia, WB Saunders Co, 1(5): 261-264.

15. Andrews AH, Blower RW, Boyd (1992) Bovine medicine, A text book of disease and husbandry of cattle, black well, UK, pp. 344-347.
16. Cooper BJ, Valentine BA (2016) Muscle and tendon, In: Maxie MG (Eds.), Jubb, Kennedy, and Palmer's Pathology of Domestic Animals. ( $6^{\text {th }}$ edn), Elsevier, pp. 164-249.

17. Useh NM, Nok AJ, Esievo KAN (2003) Pathogenesis and pathology of blackleg in ruminants: the role of toxins and neuraminidase, a short review. Vet Q 25: 155-159.

18. Kriek NPJ, Odendaal MW (2004) Clostridium chauvoei infections, In: Coetzer R, Tustin RC (Eds.), Infectious Diseases of Livestock. ( $2^{\text {nd }}$ edn), Oxford University Press, UK, 2: 1856 -1862.

19. Barros CSL (2016) Sistema muscular. In: Santos RL, Alessi AC.(Eds.), Patologia Veterinária. (2ª edn), Roca, São Paulo, pp. 663 -702.

20. Merck Veterinary Manual (2005) Whitehouse Station, NJ, Merck \& Co, pp. 488-489.

21. Jones TC, Hunt R, King NW (1978) veterinary pathology ( $6^{\text {th }}$ edn), pp. 418-893.

22. Buxton A, Fraser G (1977) Animal microbiology. ( $1^{\text {st }}$ edn), London black well scientific, UK, pp. 288.

23. Songer JG (2004) Histotoxic clostridia. In: Gyles CL, Prescott JF, Songer JG, Thoen CO (Eds.), Pathogenesis of Bacterial Infections in Animals, ( $3^{\text {rd }}$ edn), Ames, Blackwell, UK, pp. 127.

24. Hogarth (2000) Animal microbiology, ( $6^{\text {th }}$ edn), Lippincott A, D, London, UK, pp. 117.

25. Erwin BG (1986) Clostridiabl bacteria and clostridialmyosits. In current therapy in food animal practice. Howards JI (Eds.), $\left(2^{\text {nd }}\right.$ edn), pp. 567-570.

26. Russell F, Dale W Miskimins, Roland G Good, Thomas Stenberg (2009) Blackleg (Clostridium chauvoei Infection) in Beef Calves: A Review and Presentation of Two Cases with Uncommon Pathologic Presentations. The Bovine Practitioner 43: 2.

27. Hirsh (2002) Veterinary Micro biology California, USA, 1: 238.

28. Jordan MF (1988) Clostridal myosits in cattle: bacteriology and gross pathology vet Ret 100: 90-91.

29. Barnes DM (1999) Selected black leg out breaks and their relation to soil excavation. Can vet J 16: 257-259.

30. Constable PD, Hinchcliff KW, Done SH, Grunberg W (2017) A Textbook of the Diseases of Cattle, Horses, Sheep, Pigs, and Goats, (1 $11^{\text {th }}$ edn), Elsevier Ltd pp. 1431-1432.

31. Cockcroft P (2015) Bovine Medicine ( $3^{\text {rd }}$ edn), John Wiley \& Sons, pp. 575.

32. Scott (1988) Clostridium chauvoei in cattle. In infectious disease of livestock, Oxford University press, capetown, UK, 2: 1169-1172.

33. Butler HC (1998) Black leg of the fetus in ewes. JAM vet med Assoc 128: 401-402.

34. Bardford (1998) Large animal internal medicine. London, UK, 2: 1671.

35. Sarah Robson, Wilson JM (2007) Blackleg in cattle.

36. Ethiopian veterinary association proceedings of the $13^{\text {th }}$ Annual conference (1999)

37. Jimma zone Department of Agriculture and Rural development record Office (1999) E.C Annual report.

38. Hagmoster KM, Boyle T, Dandching JD (1980) Blackleg and development of multiple capsular type system, microbial, 31(2): 15-17.

39. Higbee VM (1999) Control of black leg infection vaccine 11: 1275-1279.

40. Horst SH, Sefiert (1992) Tropical animal health kluwer academic $\left(2^{\text {nd }}\right.$ edn), London, UK, pp. 289. 


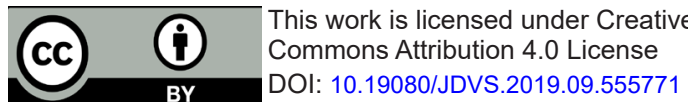

Your next submission with Juniper Publishers
will reach you the below assets
- Quality Editorial service
- Swift Peer Review
- Reprints availability
- E-prints Service
- Manuscript Podcast for convenient understanding
- Global attainment for your research
- Manuscript accessibility in different formats
( Pdf, E-pub, Full Text, Audio)
- Unceasing customer service
Track the below URL for one-step submission
https://juniperpublishers.com/online-submission.php

